\title{
Ascensão Escolar e Profissionalização de Bons Alunos de Baixa Renda: Avaliação de Um Programa Brasileiro
}

\author{
Zânia Maria Diório ${ }^{12}$ \\ Instituto Bom Aluno do Brasil, Paraná \\ Paula Inez. Cunha Gomide \\ Universidade Federal do Paraná
}

\begin{abstract}
Resumo
Esta pesquisa de avaliação de programa analisou a escolarização e a profissionalização de 629 jovens da região de Curitiba, em 2001, para detectar o efeito do programa social PBA - Programa Bom Aluno. Verificou-se a evolução da escolaridade sem interrupção nos estudos, a freqüência e o tipo de instituição formal de ensino, se pública ou privada, o exercício e o tipo de trabalho nos grupos experimental e controle. O efeito positivo do programa foi identificado no nível superior de ensino $\left(\chi^{2}=34,164\right.$; $p<0,0001)$, onde se encontrou que havia 3 vezes mais participantes do grupo controle do que do experimental que não freqüentavam a universidade. Foram identificados $62,9 \%$ de alunos do PBA, do nível superior, que trabalhavam e estudavam em comparação com apenas $37,9 \%\left(\chi^{2}=8,672 ; p=0,003\right)$ do grupo controle. Concluiu-se que as ações do PBA foram efetivas quanto a alcançar, manter o estudo, e exercer o trabalho no nível superior de ensino.

Palavras-chave: Avaliação de programas; educação; profissão; adolescente.
\end{abstract}

The Educational and Professional Development of low Income Students: Evaluation of a Brazilian Program

\begin{abstract}
This research that was carried out in order to evaluate the effect of the Program Bom Aluno, PBA, taking into consideration the educational and professional development of 629 students from Curitiba and surroundings in the year of 2001. The evolution of the schooling without interruption in the process, the attendance to classes and the kind of institution itself, private or public, and the practice and kind of work in both the control and the experimental groups were assessed. Positive effect of the Program was verified at university $\left(\chi^{2}=34,164 ; p<0,0001\right)$, where there were three times more participants from the control group that did not go to college than from the experimental group. It was found that $62,9 \%$ of the students from PBA at college level, worked and studied whereas only $37,9 \%\left(\chi^{2}=8,672 ; p=0,003\right)$ of the students from the control group did so. It was concluded that PBA was effective in helping the students to reach college, continuing the studies, and start working.

Keywords: Program evaluation; education; profession; teenager.
\end{abstract}

Consoante às estatísticas apresentadas pelo Ministério da Educação e Cultura - MEC (1996), houve uma evolução da educação brasileira nas duas últimas décadas, refletidas em um aumento da taxa média de escolaridade da população: de 2 anos de estudo em 1960, houve uma progressão para 5 anos de estudo em 1990. Ainda assim, o Brasil tem sido apontado como um dos países com menor nível de escolarização do mundo: entre os 71 milhões de brasileiros que compõem a população economicamente ativa, a média de escolarização gira em torno de 3,8 anos. Os brasileiros levam aproximadamente 11,2 anos para concluírem as 8 séries do ensino fundamental (Caixeta, 1997; MEC, 1996). Outros dados apontam que, de cada 100 estudantes, apenas 35 concluem a 8 a série, e que, dentre as variáveis que propiciam a evasão escolar, estão elencadas a repetência e a necessidade do aluno auxiliar no sustento familiar (MEC, 1996; Patto,

\footnotetext{
${ }^{1}$ Endereço para correspondência: Caixa Postal 535, 83323 990, Pinhais, PR. Fone: (41)6738030; Fax: (41)6738061.E-mail: zania@bomaluno.com.br

${ }^{2}$ Agradecimentos aos Senhores Francisco Simeão e Luiz Bonacin, idealizadores do Programa Bom Aluno, pela confiança e oportunidade para realizar esta pesquisa.
}

1993; Ribeiro,1991). As perdas educacionais resultantes do trabalho infantil e juvenil são graves, "não apenas porque não serão recuperadas ao longo da vida dos indivíduos, mas também, porque tendem a se propagar intergeracionalmente" (Souza, 2000, p. 8).

Ao se ponderar sobre a distribuição da população por nível de escolaridade, em 1990, apenas 19\% da população do País possuía o ensino fundamental, $13 \%$ o ensino médio e $8 \%$ o nível superior, sendo que esse quadro de escolarização desigual é decorrente do processo de extrema concentração de renda e de elevados níveis de pobreza (Instituto Brasileiro de Geografia e Estatística - IBGE, 2000). Desse modo, a dificuldade da evolução escolar ficou ainda exposta, principalmente quando se tem como referencial o ingresso ou a formação de nível superior da população brasileira (Instituto Nacional de Estudos e Pesquisas Educacionais - INEP, 2000a, 2000b).

A formação escolar para o trabalho e a dissonância existente entre o que faz a escola e o que a sociedade espera, traduzem um dos principais problemas para que se concretize a inserção dos jovens no mundo do trabalho 
(Sarriera \& Teixeira, 1997). Pesquisas realizadas porCasal, Masjuan e Planas (1989) indicam que na transição da escola para o trabalho, boa parte dos empregos pouco ou nada tem a ver com os estudos. É justamente esta falha para a formação no trabalho, gerada pela alta exigência do mercado laboral e pela baixa qualificação do trabalhador, tanto na educação formal quanto na formação humana, que faz surgir a necessidade de capacitação ou de desenvolvimento por intermédio do "ensino não formal" (Ferretti, 1997; Kuenzer, 2000; Lúcio \& Sochaczewski, 1998; Shiroma \& Campos, 1997).

A literatura (Camarano, Pasinato, Arruda \& Lovisolo, 2001; Kuenzer, 2000; Patto,1993; Pestana, 1999; Ribeiro,1991), freqüentemente, relata que a necessidade do trabalho se sobrepõe e afasta os jovens do mundo do estudo; em compensação, o mundo do trabalho remunera melhor aqueles que têm maior escolaridade (Delors, 2000; Rocha, 2000).

Tanto a qualificação quanto a inserção profissional da juventude têm sido estudadas no Brasil, com o intuito de identificar as razões que levam o jovem de ensino médio a iniciar prematuramente sua atividade laboral. Sarriera e Teixeira (1997) argumentam que o desinteresse pelos estudos e a autonomia quanto aos pais são causas importantes neste processo. Por outro lado, para capacitá-los ao emprego, buscase o desenvolvimento de capacidades e conhecimentos, de representações sociais e atitudes frente ao labor, de treinamento de habilidades sociais, elementos incertos nos contextos do trabalho e da cidadania (Sarriera, Câmara \& Berlim, 2000; Sarriera, Câmara, Schwarcz, De Bem \& Garandillas, 1996; Sarriera \& Teixeira, 1997).

\section{Avaliação de Programas}

No Brasil, a produção de conhecimento no que se refere à avaliação de programas do terceiro setor cresce gradativamente (Belloni, Magalhães \& Sousa, 2000). Quando se trata de avaliar uma intervenção social, é crucial selecionar um delineamento de pesquisa, no qual se garanta a comparabilidade dos grupos, $\mathrm{o}$ controle de variáveis intervenientes e a superação dos problemas de seleção diferencial (Cano, 2001). Segundo Baer (2001), o efeito de um programa é reputado pelas medidas antes-depois, demonstrando a grandeza da diferença daquilo que o programa sugere ter realizado. A relação causa-efeito (efetividade), igualmente, deve ser alvo de investigação; tal autor afirma que a relação causa-efeito remete ao fato do resultado obtido ter sido ocasionado pela ação do programa avaliado.

Entretanto, nem sempre há possibilidade de se estabelecer o grupo controle no início da pesquisa. Nesse aspecto, anote-se que a ausência do grupo controle originou as pesquisas quaseexperimentais nas áreas das Ciências Sociais. E mais: diante de tais condições, o pesquisador procura obter grupos similares para efetuar a comparação entre os participantes, de forma a manter um certo controle sobre o contexto em que se desenvolve a pesquisa (Cano, 2001; Cohen \& Franco, 1999; Novaes, 2000).
Na pesquisa de avaliação, também denominada avaliativa, a idéia é identificar o(s) impacto(s) obtido(s) pelas ações a serem avaliadas. Não se pretende buscar as relações de causalidade, tampouco caracterizá-las e compreendê-las. A maior parte das fórmulas ou modelos propostos para a aproximação e apreensão do objeto concernem à natureza quantitativa, com crescente participação da natureza qualitativa; porém, ressalte-se que esta avaliação é orientada para a objetividade, demais de visibilizar uma possibilidade de generalização do observado. Aliás, é de se sublinhar que neste tipo de pesquisa o objetivo primordial é a produção de um conhecimento que seja reconhecido como tal pela comunidade científica (Cohen \& Franco, 1999; Novaes, 2000).

\section{O Programa Bom Aluno}

OPrograma Bom Aluno (PBA) surgiu em 1993 e foi idealizado para garantir a melhoria das condições de estudo de jovens bons alunos de baixa renda. Este programa é uma iniciativa de empresários paranaenses; logo, a partir deste apoio educacional, o PBA pretendeu melhorar a condição social de seus integrantes, preparando-os e, posteriormente, inserindo-os no mercado de trabalho. Os procedimentos educacionais do PBA permitem que seus alunos realizem um estudo de qualidade e sem interrupções. Além disso, cursos de inglês, computação, desenvolvimento de habilidades sociais e de estudo, entre outros, são oferecidos aos educandos.

O PBA seleciona estudantes da $5^{a}$ série da rede pública de ensino, oriundos de familias de baixa renda (com renda familiar que não ultrapasse 6 salários mínimos), cujas notas escolares são iguais ou maiores que sete $(7,0) \mathrm{em}$ todas as matérias e oferece à sua clientela condições e estímulos para que obtenham formação educacional e profissional; seu alcance se estende até os níveis de graduação. Demais disso, o Programa prevê recursos financeiros para que $10 \%$ dos formandos possam realizar cursos de pós-graduação, inclusive no exterior. Tal recurso está disponível para os alunos formados que tenham interesse em cursos de pós-graduação e que logrem êxito em se credenciar paratanto.

Após 10 anos de funcionamento, a equipe do PBA decidiu efetuar uma pesquisa avaliativa (Diório, 2002) que respondesse à seguinte questão: Qual o efeito do Programa Bom Aluno sobre a escolarização e a profissionalização dos participantes do Programa?

\section{A pesquisa}

A pesquisa foi realizada dentro de um modelo quaseexperimental, já que a constituição do grupo controle ocorreu $a$ posteriori (Baer, 2001; Cohen \& Franco,1999; Novaes, 2000) e o foco concentrou-se na identificação do efeito obtido pelas ações do PBA sobre a escolarização e profissionalização de seus participantes, nos grupos experimental e controle, durante o ano de 2001 (Diório, 2002). 
O grupo controle foi composto por alunos que apresentavam perfil escolar semelhante ao dos estudantes que ingressaram no PBA, ou seja, com nota mínima de 7,0 em todas as matérias, em todos os anos escolares, provenientes de escolas públicas estaduais e municipais de Curitiba e de cidades circunvizinhas. As escolas escolhidas foram as mesmas freqüentadas pelos alunos do PBA. Os participantes foram selecionados dentre familias com faixa salarial similar a do grupo experimental.

Com efeito, a avaliação englobou três campos de investigação, quais sejam: escolarização, profissionalização e relação entre a escolarização e a profissionalização. A escolarização compreendeu a análise da escolaridade inicial (série escolar na qual o participante estava no momento em que foi admitido no PBA), a escolaridade ideal (ano escolar em que o aluno deveria estar em 2001, caso não ocorresse nenhum tipo de interrupção em seus estudos) e a escolaridade atual (série em que o aluno se encontrava em 2001, independentemente da situação de interrupção nos estudos). A avaliação da escolaridade foi feita mediante comparação do grupo experimental com o controle, quanto à interrupção ou não dos estudos durante a vida escolar. Obtida a escolaridade atual, comparava-se esta à escolaridade ideal. Tal procedimento permitiu apontar o sucesso de cada participante em termos evolutivos, sem interrupção dos estudos.

No tocante à profissionalização, procurou-se levantar as atividades laborais de cada participante, a conexão com a área de estudo e se as diferenças entre elas estariam vinculadas à ação do PBA. A relação entre escolarização e profissionalização foi avaliada via comparação entre o grupo experimental e o controle, quanto a estar ou não trabalhando, demais de correlacionada com o fato de estar ou não estudando.

\section{Método}

\section{Participantes}

Participaram da pesquisa 629 estudantes, divididos em um grupo experimental e um grupo controle. $O$ primeiro foi constituído por 275 participantes, os quais ingressaram no PBA entre 1994 e 2000, com idades, à época de sua inclusão, entre 10 e 16 anos, conforme a série de admissão. A esse grupo pertenciam os alunos permanentes $(n=177)$ e aqueles que deixaram de pertencer ao quadro do Programa até 2000 , os desligados $(n=98)$. O grupo controle foi composto por 354 participantes com perfil semelhante ao do grupo experimental, em conformidade com o descrito acima.

\section{Instrumentos}

Os instrumentos usados para a coleta de dados constituíramse de 4 formulários: a) Formulários para coletar os dados iniciais: registro de notas escolares, idade e renda familiar, tomando-se por base o ano de ingresso no PBA, tanto para o grupo experimental como para o controle; b) Roteiro de entrevistas aplicadas para os 2 grupos pesquisados para esclarecimento de dados pessoais, da condição de estar ou não estudando, do tipo de instituição e série freqüentada ou que freqüentava antes de abandonar os estudos, de reprovações, sobre interrupção nos estudos e motivos, de quantas vezes prestou vestibular até entrar no ensino superior, sobre a vida laboral - a condição de estar ou não trabalhando, a atividade desenvolvida e desde quando a iniciou.

\section{Procedimento}

Os dados do grupo experimental foram coletados em dois momentos distintos: conforme o ano escolar que o aluno cursava no ato de ingresso no PBA (dados iniciais) e de acordo com a situação de escolaridade e de trabalho em 2001; o contato com os alunos desligados do PBA, ou com seus parentes diretos (pais ou irmãos), deu-se por telefonemas, carta ou pessoalmente. Os dados iniciais (histórico escolar, de renda e informações pessoais) do grupo controle foram conseguidos nas escolas públicas e, os finais, por intermédio de entrevistas telefônicas com os próprios participantes da pesquisa ou com seus parentes diretos. Os dados foram digitados no programa Statistical Packeage for the Social Sciences (SPSS) para viabilizar as comparações através dos testes não paramétricos "Comparação de duas proporções" e "Qui-quadrado para uma única amostra". O nível de significância adotado foi de $5 \%(p<0,05)$.

\section{Resultados}

A comparação a partir de análises estatísticas, dos grupos experimental e controle, forneceu resultados reveladores de sua situação de escolarização e profissionalização em 2001, os quais possibilitaram estabelecer relações entre essas variáveis.

\section{Escolarização: Evolução sem Interrupção nos Estudos}

A Figura 1 comparou os grupos experimental e de controle, quanto a não interrupção dos estudos, a partir do ano escolar inicial e do ano escolar atual, por nível de ensino. Observou-se uma diferença estatisticamente significativa entre os grupos no ensino superior $\left(\chi_{\text {calc }}^{2}=34,164 ; p<0,0001\right)$, onde se vê que 57

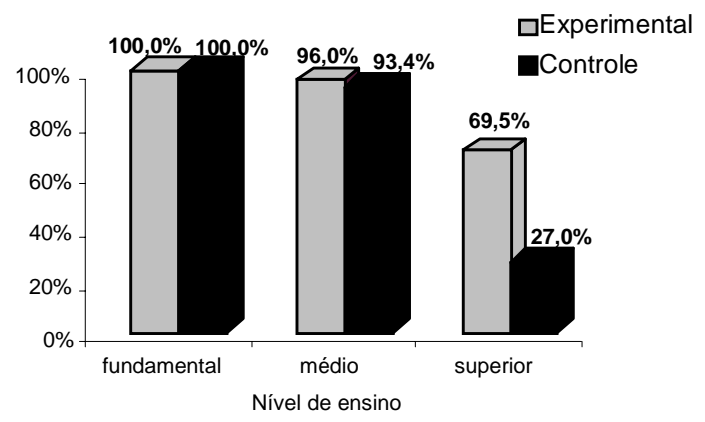

Figura 1. Distribuição dos grupos, por níveis de ensino, com relação aos participantes que nunca interromperam seus estudos. 
(69,5\%) participantes do grupo experimental nunca interromperam seus estudos, enquanto que apenas $33(27 \%)$ do grupo controle se mantiveram estudando.

Os dados sugerem que as ações do PBA são efetivas no nível superior; já nos níveis fundamental e médio não ocorreram diferenças de desempenho entre os dois grupos estudados.

A distribuição dos dados na Figura 1 indicou que alguns estudantes interromperam seus estudos, não atingindo o nível superior. Em função disto, avaliou-se o momento desta interrupção. A Tabela 1 demonstrou quando ocorreu a interrupção nos estudos. Observou-se que os alunos que ingressaram no nível fundamental, em ambos os grupos, não pararam de estudar. A análise estatística revelou que a diferença foi significativa entre estudantes do nível médio $\left(\chi_{\text {calc }}^{2}=5,110\right.$; $p=0,024)$, onde prevaleceu a categoria "estuda" no grupo experimental $(90,3 \%)$ em comparação aos 80,9\% do controle. Este dado pode sugerir que o PBA tem uma ação deveras efetiva sobre seus alunos, evitando que interrompam seus estudos. Outro dado interessante aparece quando se analisa o comportamento dos universitários, nos dois grupos: verificou-se que após atingir este nível de escolaridade, os estudantes não mais abandonam os estudos.

Os motivos que levaram os participantes a parar de estudar, segundo seu próprio depoimento, estão elencados na Tabela 2. Para o grupo experimental, as razões de interrupção dos estudos foram variadas e as opiniões se dispersaram, representadas pela categoria "outro motivo", com 3,5\% (gravidez, casamento, serviço militar, problema de saúde, falta de motivação, viagem a trabalho, ingresso na faculdade em outra cidade, insegurança para prestar vestibular). Já para o grupo controle, o motivo principal foi a "reprovação no vestibulare falta de condições para pagar cursinho ou faculdade particular", com 7,4\% das respostas, seguido por "estudar e trabalhar é muito cansativo" e "necessidade de ajudar no sustento da famillia ou obter o próprio sustento", ambos com $2,8 \%$ de respostas.

A reprovação no vestibular e a falta de condições financeiras são justamente os dois fatores que distinguem os grupos; por um lado, o grupo experimental é apoiado financeiramente pelo PBA e, em contrapartida, o grupo controle enfrenta as dificuldades financeiras naturais da classe social a que pertence.

\section{Condição de trabalho em 2001}

Foram encontrados 193 participantes trabalhando e, destes, 78 pertenciam ao grupo experimental e 115 ao grupo controle. Analisando-se os dados em função dos três níveis de ensino, observou-se que somente no nível superior a diferença entre os grupos foi estatisticamente significativa $\left(z_{c}=6,22 ; p=0,012\right)$, isto é, os alunos do PBA $(56,41 \%)$ apresentaram uma maior proporção de trabalhadores que os participantes do grupo controle $(28,70 \%)$, como pode ser visto na Figura 2. É importante comentar que apesar do apoio financeiro dado pelo PBA, os alunos são incentivados ao trabalho, de forma que tal procedimento poderá estar sendo responsável por esta diferença nos dados.

Tabela 1

Condição de Estudo de acordo com os Niveis de Ensino

\begin{tabular}{llccc}
\hline \multirow{2}{*}{ Grupo } & \multirow{2}{*}{ Condição } & & Nível de ensino & \\
\cline { 5 - 5 } & & fundamental & médio & superior \\
\hline \multirow{2}{*}{ Experimental } & Estuda & $69(100 \%)$ & $130(90,3 \%)$ & $62(100 \%)$ \\
& Não estuda & $0(0 \%)$ & $14(9,7 \%)$ & $0(0 \%)$ \\
& Estuda & $82(98,8 \%)$ & $174(80,9 \%)$ & $55(98,2 \%)$ \\
& Não estuda & $1(1,2 \%)$ & $41(19,1 \%)$ & $1(1,8 \%)$ \\
\hline
\end{tabular}

Tabela 2

Motivo de Interrupção do Estudo no Ensino Médio

\begin{tabular}{lcc}
\hline & \multicolumn{2}{c}{ Grupo } \\
Motivo de Interrupção & Experimental & Controle \\
\hline Estudar e trabalhar é muito cansativo & $0(0 \%)$ & $6(2,8 \%)$ \\
Incompatibilidade de horário de estudo e trabalho & $1(0,7 \%)$ & $2(0,9 \%)$ \\
Reprovação no vestibular e falta de condições para pagar & $4(2,8 \%)$ & $16(7,4 \%)$ \\
$\begin{array}{l}\text { cursinho ou faculdade particular } \\
\text { Reprovação no ensino fundamental ou médio }\end{array}$ & $0(0 \%)$ & $2(0,9 \%)$ \\
Necessidade de ajudar no sustento da família ou obter o & $4(2,8 \%)$ & $6(2,8 \%)$ \\
próprio sustento & & \\
Outro motivo & $5(3,5 \%)$ & $9(4,2 \%)$ \\
\hline
\end{tabular}




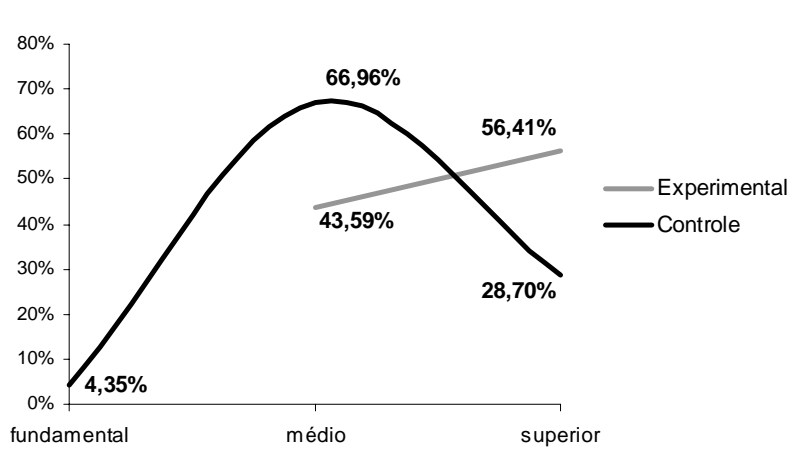

Figura 2. Distribuição dos participantes, que trabalhavam em 2001, por nível de ensino.

\section{Tipo de trabalho em 2001}

Os dados sobre o tipo de trabalho, vistos na Tabela 3, revelaram, num primeiro momento, que a totalidade dos alunos do PBA e a grande maioria dos do grupo controle que estão no nível fundamental, não trabalham. Esta informação é muito importante e confortadora, visto que existe todo um esforço da sociedade e da legislação vigente (Estatuto da Criança e do Adolescente - ECA, 1990), no sentido de proibir o trabalho infantil, favorecendo, portanto, a escolarização.

No nível médio já se pôde observar uma maior distribuição de participantes entre os tipos de trabalhos, porém com uma concentração significativa no item "não trabalha" para os dois grupos (76,4\% do grupo experimental e $64,2 \%$ do controle). Observou-se, também, que 1/4 dos que trabalham fora de sua área de estudo são do grupo controle $(25,1 \%)$, com uma menor parcela do grupo experimental $(16 \%)$.

No nível superior predominou a atividade de estágio (40\%) no grupo experimental em comparação a $25 \%$ do controle. Entre os universitários, $41 \%$ dos alunos do grupo controle não trabalhavam, contra apenas $29 \%$ dos alunos do PBA. Este dado deve ser analisado em conjunto com a atividade de estágio desenvolvida por eles, ou seja, os alunos do PBA estão

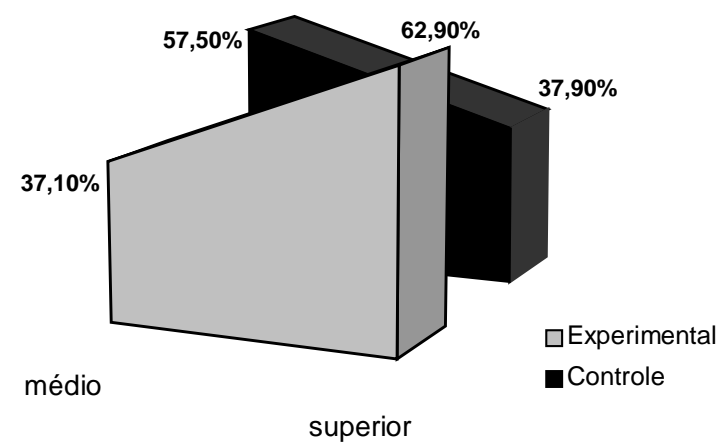

Figura 3. Alunos que estudavam e trabalhavam, nos grupos de ensino médio e superior.

complementando sua formação profissional em estágios vinculados às suas áreas de atuação, enquanto que os demais buscam trabalho entre os empregos disponíveis.

\section{Trabalho: relação entre os níveis médio e superior}

Foi realizada uma análise da sub-amostra (controle: $n=83$; experimental: $n=70$ ) dos participantes dos níveis médio e superior de ensino, os quais estudavam e trabalhavam, simultaneamente (Figura 3). Há uma relação inversamente proporcional do nível médio para o superior entre os grupos; enquanto que para o grupo controle a curva é decrescente (de $57,50 \%$ para $37,90 \%$ ), no grupo experimental o sentido da curva é crescente $(37,1 \%$ para $62,9 \%)$.

Observou-se o predomínio dos estudantes do grupo controle que trabalhavam no nível médio de ensino $(\chi 2$ calc $=5,630 ; p=0,018)$ e, também, uma diferença a favor dos alunos do PBA que trabalhavam e cursavam o ensino superior $(\chi 2 \mathrm{calc}=8,672 ; p=0,003)$. Tais distinções, estatisticamente significativas, podem ser atribuídas ao efeito do PBA, onde a inserção ao trabalho faz parte de seu planejamento programático, efetivado basicamente durante o período em que os alunos cursam a universidade.

Tabela 3

Tipos de Trabalho nos Grupos Pesquisados, em 2001

\begin{tabular}{llcccccc}
\hline Grupos & Tipo & \multicolumn{2}{c}{ Fundamental } & \multicolumn{2}{c}{ Médio } & \multicolumn{2}{c}{ Superior } \\
\cline { 2 - 8 } & & $\mathrm{N}$ & $\%$ & $\mathrm{~N}$ & $\%$ & $\mathrm{~N}$ & $\%$ \\
\hline \multirow{5}{*}{ Experimental } & não trabalha & 69 & $100 \%$ & 110 & $76,4 \%$ & 118 & $29,0 \%$ \\
& faz estágio & 0 & - & 7 & $4,9 \%$ & 25 & $40,3 \%$ \\
& trabalha na área de estudo & 0 & - & 4 & $2,8 \%$ & 8 & $12,9 \%$ \\
& trabalha em outra área & 0 & - & 23 & $16,0 \%$ & 11 & $17,7 \%$ \\
& Total & 69 & & 144 & & 62 & \\
\hline \multirow{5}{*}{ Controle } & não trabalha & 78 & $94,0 \%$ & 138 & $64,2 \%$ & 23 & $41,1 \%$ \\
& faz estágio & 0 & - & 14 & $6,5 \%$ & 14 & $25,0 \%$ \\
& trabalha na área de estudo & 0 & - & 9 & $4,2 \%$ & 0 & $0,0 \%$ \\
& trabalha em outra área & 5 & $6,0 \%$ & 54 & $25,1 \%$ & 19 & $33,9 \%$ \\
& Total & 83 & & 215 & & 56 & \\
\hline
\end{tabular}




\section{Ensino superior público versus privado}

A maioria dos estudantes, independentemente do grupo, freqüentava instituição particular de ensino superior, segundo a Figura 4 (70,5\% para o experimental e $78,8 \%$ para o controle). $\mathrm{O}$ dado mais expressivo de diferenciação entre os grupos pesquisados, diz respeito à instituição pública, na qual o grupo experimental se distribuiu igualitariamente entre exercer ou não atividade laboral, enquanto que o controle, cujos integrantes estudavam em instituição pública, não trabalhava em sua maioria $(63,6 \%)$.

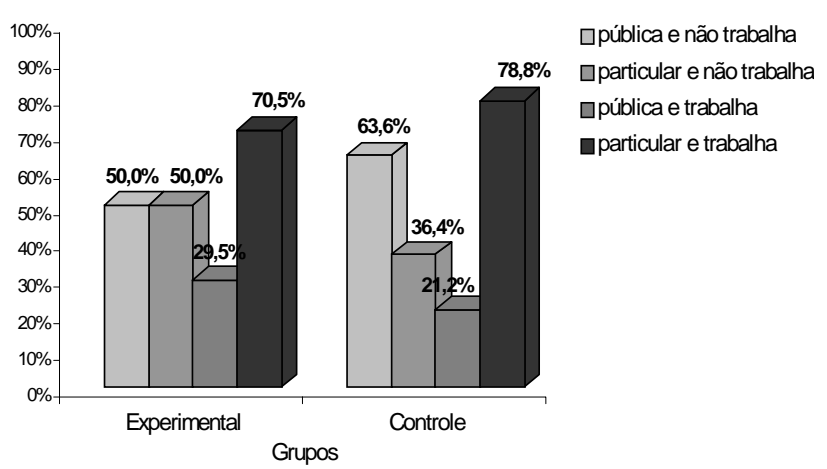

Figura 4. Distribuição dos grupos pesquisados de acordo com o trabalho e o tipo de instituição no nível superior.

As mensalidades dos estudantes do PBA eram mantidas pelo Programa enquanto que as do controle eram pagas pelos próprios alunos, que freqüentavam instituição privada e trabalhavam, de modo majoritário, provavelmente para manter seus estudos. Entrementes, observou-se que os universitários do grupo controle que freqüentavam instituições públicas, em sua maior parte, não trabalhavam.

\section{Discussão}

No que diz respeito à imagem do "bom aluno", existe um contraponto entre o "senso comum" e a ciência, como afirma Rangel (1997). A autora diz que a atribuição muitas vezes feita ao "bom aluno" lhe institui o peso e a responsabilidade de "ir sozinho", como se as condições sócio-histórico-econômicas não se impusessem a ele, nos papéis de variáveis intervenientes ao seu processo de conquista de "um lugar ao sol". Bons alunos de baixa renda, quando incentivados a quebrar o bloqueio sóciofinanceiro que os restringem, são capazes de evoluir em sua escolaridade com melhores resultados, conquistam postos de trabalho inclusive ligados à sua área de estudo, atuam com efetividade no nível superior. Jovens com alta especialização estarão mais qualificados para desempenhar atividades laborais e obter salários melhores, uma vez comparados àqueles que não dispõem de recursos (Aquino, 1997; Caillods, 1994; Cepal, 1994; Ferretti, 1997; Lúcio \& Sochaczewski, 1998).
O Programa Bom Aluno demonstrou um efeito positivo quanto ao acompanhamento de alunos sem a interrupção dos estudos, quer por abandono ou reprovação, mostrando uma maior porcentagem de estudantes que chegaram ao nível superior de ensino (69,5\% para o grupo do PBA e $27 \%$ para o controle). Em todos os anos que os alunos do Programa prestaram vestibular em Curitiba/PR, 100\% ingressaram na universidade, sendo a média de aprovação na universidade pública (Universidade Federal do Paraná UFPR e Centro Federal de Educação Tecnológica do Paraná - CEFET-PR) de aproximadamente $50 \%$.

De acordo com os índices nacionais, o maior número de evasão escolar concentra-se no nível fundamental (Caixeta, 1997; IBGE, 1997, 2000; MEC, 1996); demais disso, cumpre grifar que o incentivo para o aumento de escolaridade em nosso País só teve início em meados de 1996 (INEP, 2000a, 2000b). Entretanto, o acesso ao nível superior ainda é reservado àqueles de renda mais alta, ressalvados os exemplos em que o esforço do próprio aluno garantiu sua conquista (Comissão Central do Concurso Vestibular da UFPR, 2002; Kuenzer, 2000). Aparentemente, segundo os dados desta pesquisa, ser um bom aluno altera a condição de abandono no ensino fundamental. No caso da população de "bons alunos" do grupo controle, verificou-se que a evasão escolar ocorreu ao final do ensino médio, atrasando seu ingresso no ensino superior, o que não ocorreu no grupo experimental. Já as razões que levaram o grupo controle a abandonar os estudos referiram-se à reprovação no vestibular e à falta de condições econômicas para freqüentar um curso pré-vestibular e de nível superior na rede particular de ensino.

$\mathrm{O}$ investimento do PBA no ensino superior visa possibilitar a seus integrantes um nível de qualificação diferenciado, que favoreça a sua inserção em altos postos de trabalho, potencializando sua remuneração. Com isso, a expectativa do Programa é que ocorra uma melhoria da condição social do aluno, bem como de sua família. Peliano (2000) comenta que os programas sociais do Sudeste brasileiro constituem-se num verdadeiro movimento em prol dos mais necessitados, caracterizam-se muito mais pela propositura de um programa de cunho assistencial do que por um investimento na melhoria da qualidade de uma mão-de-obra potencial. E mais: destaca que essas ações assistenciais e emergenciais devem ser complementadas por atividades capazes de promover tanto o desenvolvimento humano quanto social daqueles que são assistidos.

Ainda, ao se estabelecer um nexo entre a alta qualificação e o nível de ensino, pesquisas demonstram que a grande maioria da população tem acesso apenas à educação básica, fundamental e média, o que leva ao exercício de tarefas precárias na informalidade ou no mercado formal, e que a oferta de educação científico-tecnológica (pós-médio à pós-graduação) fica restrita a um pequeno número de trabalhadores (Kuenzer, 2000). 
Nesse quadrante, a autora também menciona que, enquanto os países desenvolvidos apresentam índices elevados de educação superior, no Brasil as empresas têm assumido a escolarização dos trabalhadores, devido à insuficiência das políticas públicas.

Investir em alunos com bom desempenho escolar, como o faz o PBA, permite que o apoio financeiro iniba o abandono e o fracasso escolar que podem acometer mesmo os mais motivados e competentes nesta área. Caillods (1994) salienta que os jovens que fracassaram em sua escolaridade regular ou foram dela excluídos, tenderão a engrossar o contingente dos que só encontram trabalho no setor não-estruturado da economia, mormente quando a tais exigências se somam os requisitos de formação geral sofisticada, priorizados pelas empresas inovadoras.

O aumento da condição "só trabalha" e a conseqüente diminuição do estudo na medida em que a idade aumenta, revelaram que a necessidade do trabalho vai se sobrepondo e afastando os jovens do universo escolar, em especial, nas fases do ensino médio e superior (Camarano \& cols., 2001; IBGE, 2000; Kuenzer, 2000; Patto, 1993; Pestana, 1999; Ribeiro, 1991). Nesta pesquisa, observou-se uma parcela significativa de abandono dos estudos entre os participantes do grupo controle; já os dados pertinentes ao grupo experimental expuseram uma realidade inversa, em que os melhores resultados na relação trabalho e estudo apareceram no ensino superior.

O Programa Bom Aluno pretendeu colocar à disposição dos seus alunos dispositivos pedagógicos que favorecessem a melhoria de sua condição social. Parte desta mudança social poderá ser obtida mediante qualificação profissional, qualidade de emprego e nível salarial dos participantes. Outra parcela disto poderá ocorrer via uma melhoria das habilidades sociais e nível de conhecimento geral de inglês, computação, etc., dos participantes. Os programas sociais que pretendem ampliar oportunidades para a transformação social devem disponibilizar aos seus participantes um conjunto de habilidades e conhecimentos, capazes de garantir condições mínimas que aumentem as chances do indivíduo vencer obstáculos e obter uma condição de vida familiar e social mais apropriada à felicidade do ser humano.

Futuramente, poder-se-á avaliar o efeito dos programas específicos de desenvolvimento de habilidades do PBA relacionados à formação humana, tais como a construção da autonomia, o desenvolvimento das capacidades adaptativas e de competências humanas para a vida social e produtiva, bem como dos cursos de capacitação (inglês, espanhol, vivência internacional, etc.), no que suspeita ao mercado de trabalho dos grupos pesquisados. É preciso ainda que se avalie o impacto causado pelo PBA sobre a empregabilidade, nível salarial e qualificação profissional dos participantes.
A avaliação de programas sociais, a exemplo do Programa Bom Aluno, é necessária para que se amplie o conhecimento sobre o que é feito, agregando-se a construção do conhecimento científico a um modelo de intervenção. $\mathrm{O}$ conhecimento sobre a realidade que se apresenta, tem uma razão de ser e, no caso de programas sociais, destina-se a possibilitar o fortalecimento de uma nação, que sem dúvida é um caminho importante a ser percorrido.

O Programa Bom Aluno é uma alternativa que inibe a evasão escolar e a baixa qualificação profissional, situações essas profundamente vivenciadas por milhões de cidadãos. A sociedade brasileira, ao compartilhar idéias, poderá contribuir para a transformação e progresso educacional do País. Eis que aí se manifesta um desafio que os educadores estarão sempre dispostos a enfrentar.

\section{Referências}

Aquino, J. G. (Org.) (1997). Erro e fracasso na escola. São Paulo: Summus.

Baer, D. M. (2001, setembro). Evaluating autism programs: A special case of program evaluation. Trabalho apresentado no $10^{\circ}$ Encontro da Associação Brasileira de Psicologia e Medicina Comportamental, Campinas, SP.

Belloni, I., Magalhães, H. \& Sousa, L. C. (2000). Metodologia de avaliação em políticas públicas: Uma experiência em educação profissional. São Paulo: Cortez.

Caillods, F. (1994). Rasgos convergentes en el mosaico de sistemas de formación profesional. Revista Internacional del Trabajo, 113, 279-297.

Caixeta, N. (1997). Como virar a página. Brasilem Exame, setembro, 6-11.

Camarano, A. M., Pasinato, M. T., Arruda, M. R. \& Lovisolo, N. E. (2001). Osjovens brasileiros no mercado de trabalho [On-line]. Disponível: www.balancosocial.org.br

Cano, J. I. (2001). Elaboração de um texto introdutório sobre avaliação de programas sociais e sua aplicação a educação [On-line]. Disponível: www.race.ie.ufrj.br

Casal, J., Masjuan, J. M. \& Planas, J. (1989). La inserción profesionaly social de los jóvenes: Los itinerarios de transición entre los 14 y los 25 años. Barcelona: Inprenta Juvenil.

Cohen, E. \& Franco, R. (1999). Avaliação de projetos sociais. Petrópolis, RJ: Vozes.

Comisión Económica para América Latina y el Caribe - Cepal (1994). Capacitación en América Latina: Algunos desarrollos recientes, comparaciones internacionales y sugerencias depolitica. Santiago, Chile: Cepal.

Comissão Central do Concurso Vestibular- CCCV (2002). Relatório do questionário sócio-educacional- Concurso Vestibular 2002. Universidade Federal do Paraná, Curitiba, PR.

Delors, J. (Org.) (2000). Educação: Um tesouro a descobrir-Relatório para a UNESCO da Comissão Internacional sobre Educação para o século XXI (4 ed.). São Paulo: Cortez; Brasília, DF: MEC, UNESCO.

Diório, Z. M. (2002). O efeito do Programa Bom Aluno sobre a escolarização e a profissionalização de alunos. Dissertação de mestrado não-publicada, Programa de Pós-Graduação em Psicologia da Infância e da Adolescência, Universidade Federal do Paraná. Curitiba, PR.

Estatuto da Criança e do Adolescente-ECA (1990). Lei no 8.069 [On-line]. Disponível: wnm.planalto.gov.br/ccivil_03/Leis/L8069.htm

Ferretti, C.J. (1997). Educação profissional e reforma do ensino técnico no Brasil: Anos 90. Educação \& Sociedade [On-line], 18. Disponível: wmw.scielo.br

Instituto Brasileiro de Geografia e Estatística - IBGE (1997). Analfabetismo [Online].Disponível: www.ibge.gov.br

Instituto Brasileiro de Geografia e Estatística - IBGE (2000). Indicadores Sociais 2000 [On-line]. Disponível: mmm.ibge.gou.br

Instituto Nacional de Estudos e Pesquisas Educacionais- INEP (2000a). Resultados e tendências da educação superior no Brasil [On-line]. Disponível: wmw.inep.gov.br

Instituto Nacional de Estudos e Pesquisas Educacionais - INEP (2000b). Aumenta número de vagas nas universidades federais [On-line].Disponível:mmw.inep.gov.br 
Kuenzer, A. Z. (2000). O ensino médio agora é para a vida: Entre o pretendido, o dito e o feito. Educação \& Sociedade [On-line], 21. Disponível: www.scielo.br

Lúcio, C. G., \& Sochaczewski, S. (1998). Experiência de elaboração negociada de uma política de formação profissional. Educação \& Sociedade [On-line], 19. Disponível: wnm.scielo.br

Ministério da Educação e Cultura- MEC (1996). Estatísticas da educação básica no Brasil (Extraído do Relatório para a Conferência Internacional de Educação em Genebra, 1996) [On-line]. Disponível: www.mec.gov.br

Novaes, H.M.D. (2000). Avaliação de Programas, serviços e tecnologias em saúde. Revista de Saúde Pública [On-line], 34. Disponível: wnw.scielo.br

Patto, M. H. S. (1993). A produção do fracasso escolar: Histórias de submissão e rebeldia. São Paulo: Queiroz.

Peliano, A. M. T. M. (Org.) (2000). A iniciativa privada e o espírito público: Um retrato da ação social das empresas do sudeste brasileiro. Pesquisa IPEAResultado final [On-line]. Disponível: www.ipea.gov.br

Pestana, M. I. G. de S. (1999). Avaliação educacional: O sistema nacional de avaliação da educação básica. Em E. M. Rico (Org.), Avaliação de políticas sociais: Uma questão em debate (pp. 53-63). São Paulo: Cortez.

Rangel, M. (1997). “Bom aluno” real ou ideal. Petrópolis, RJ: Vozes.

Ribeiro, C. (1991). A pedagogia da repetência. Estudos Avançados, 5, 7-21.
Rocha, S. (2000). Pobreza e desigualdade no Brasil: O esgotamento dos efeitos distributivos do Plano Real (Texto para Discussão n. 721) [On-line]. Disponível: www.pea.gov.br

Sarriera, J. C., Câmara, S. G., Schwarcz, C., De Bem L. A. \& Garandillas, M. (1996). Bemestar psicológico dos jovens porto-alegrenses. Psico, 27, 79-95.

Sarriera, J. C. \& Teixeira, R. P. (1997). Itinerários descritivos e diferenciais de transição da escola ao trabalho dos jovens de Porto Alegre. Psico, 28, 117-137.

Sarriera, J. C., Câmara, S. G. \& Berlim, C. S. (2000). Elaboração, desenvolvimento e avaliação de um Programa de Inserção Ocupacional para Jovens Desempregados. Psicologia: Reflexão e Crítica [On-line], 13. Disponível: mnn.scielo

Shiroma, E. O. \& Campos, R. F. (1997). Qualificação e reestruturação produtiva: Um balanço das pesquisas em educação. Educação \& Sociedade [On-line], 18. Disponível: monu.scielo.br

Souza, M. M. C. de (2000). A importância de se conhecer melhor as famílias para a elaboração de políticas sociais na América L atina. Rio de Janeiro: IPEA - Instituto de Pesquisa Econômica Aplicada.

Sobre as autoras

Zânia Maria Diório é Psicóloga do Instituto Bom Aluno do Brasil, Paraná. É Mestre em Psicologia da Infância e da Adolescência pela Universidade Federal do Paraná.

Paula Inez Cunha Gomide é Doutora em Psicologia Experimental pela Universidade de São Paulo. É Professora da Universidade Federal do Paraná. 